\title{
Cerebellopontine angle epidermoid cysts: a report on 30 cases
}

\author{
C E deSOUZA, ROSEMARIE deSOUZA, SADE DA COSTA, NEIL SPERLING, \\ TAE H YOON, M M ABDELHAMID, R R SHARMA, A GOEL
}

From the KEM Hospital, Bombay, India

SUMMARY Thirty cases of cerebellopontine angle epidermoid cysts treated over a period of 20 years are reviewed with regard to their clinical features, the pathophysiology of their symptoms and their management. The predominating symptoms were related to the 7 th and 8 th cranial nerves and headaches. The signs and symptoms were present for an average period of 4 months. It was not always possible to determine if the signs and symptoms were due to local involvement by the epidermoid, increased intracranial pressure, or both. Diagnostic procedures evolved from angiography and ventriculography to non-invasive computed tomography and MRI. The posterior cranial fossa approach was used in 27 cases. Total excision of the epidermoid was the aim and was carried out in five $(18 \%)$ patients but concern regarding the preservation of nearby important neurovascular structures forced partial removal in 22 patients. To minimise reformation, the residual epidermoid was carefully coagulated with the aid of the operating microscope and bipolar cautery without damaging surrounding neurovascular structures.

Epidermoids consist of epidermal and connective tissue structures usually in the form of a sac. They have the capacity for independent progressive growth often at the expense of neighbouring bone and have a tendency to reform after removal. The sac is lined by stratified squamous epithelium and contains epithelial debris.

Epidermoids are uncommon lesions of the central nervous system..$^{1-3}$ The cerebellopontine angle is the most common site of occurrence of intracranial epidermoids, ${ }^{45}$ and account for $9 \%$ of tumours in the cerebellopontine angle, second only to acoustic neuromas. Other reported sites include the optic chiasma, diploë of the skull and the posterior fossa.

We report experience with the behaviour and management of 30 epidermoids of the cerebellopontine angle seen over a period of 20 years. We also briefly describe a previously unreported surgical technique employed during the excision of these lesions which involved the use of the operating microscope and bipolar diathermy for the cauterisation of epithelial remnants to minimise reformation of the epidermoid.

Address for reprint requests: Dr Rosemarie deSouza, St Peters Colony, 16 Xavier House, Manuel Gonsalves Marg, Bandra, Bombay 400050 , India.

Received 8 March 1988 and in revised form 18 June 1988 Accepted 10 October 1988

\section{Materials and methods}

In this retrospective study, 30 cases of cerebellopontine ang epidermoids, seen between 1966 and 1986 in the Neurosur gery Department of the KEM Hospital, Bombay (India), are reviewed and discussed. Of these 30 patients, 19 were males and 11 were females. The mean age at presentation was 27 years. The youngest patient was 8 years old and the oldest was 60 years old.

\section{Clinical data}

For the sake of convenience, we divided the signs and symptoms into three groups, those which localised the lesion to the cerebellopontine angle, those which indicated extension beyond it, and those that indicated raised intracranial tension. It was not always possible to determine if the symptoms and signs were caused by local pressure or raised intracranial tension, or both. Most signs and symptoms presented on the ipsilateral side of the lesion except in two cases.

Localising symptoms and signs (Table 1)

The 7 th cranial nerve was involved in 16 patients. Of these 12 displayed a lower motor neuron facial weakness and one a complete lower motor neuron facial palsy, caused by local involvement by the epidermoid. The remaining three patients had an upper motor neuron weakness, believed to be caused by raised intracranial tension. The 8 th cranial nerve symptoms most commonly observed were diminished hearing in 15 and tinnitus in seven patients. Audiometry was done in six of these patients, all of which showed a severe unilateral sensorineural hearing loss. 
Table 1 Localising symptoms and signs of cerebellopontine angle epidermoids

\begin{tabular}{|c|c|c|}
\hline \multicolumn{2}{|c|}{ Symptoms } & Signs \\
\hline 1. & $\begin{array}{l}\text { Weakness/paralysis of } \\
\text { muscles of facial } \\
\text { expression \& eyelids-16 }\end{array}$ & $\begin{array}{l}\text { 1. 7th cranial nerve paresis/ } \\
\text { paralysis, lower motor } \\
\text { neurone-13 }\end{array}$ \\
\hline 2. & $\begin{array}{l}\text { Diminished hearing-15 } \\
\text { tinnitus }-7\end{array}$ & 2. 8th cranial nerve deficit -15 \\
\hline & $\begin{array}{l}\text { Vertigo-13 imbalance- }-13 \\
\text { Wasting of muscles of } \\
\text { mastication }-8 \\
\text { Trigeminal neuralgia }-4\end{array}$ & $\begin{array}{l}\text { 3. Cerebellar involvement-13 }-13 \\
\text { 4. 5th cranial nerve deficit }-11\end{array}$ \\
\hline
\end{tabular}

Eleven patients presented with involvement of the 5th cranial nerve. The mandibular division was affected in eight patients and was manifested as wasting of the muscles of mastication. Trigeminal neuralgia was seen as a less common feature in four patients. Thirteen patients complained of vertigo. Vertigo was invariably associated with cerebellar nystagmus, ataxia, dysdiadochokinesia and other cerebellar signs and was thus felt to be cerebellar in origin. The function of the labyrinth was gradually compromised due to pressure on the 8th nerve. This enabled gradual compensation by the contralateral labyrinth making vertigo of labyrinthine origin less likely. Surgical findings confirmed the cerebellum to be involved in most patients who presented with vertigo.

Signs and symptoms of extension (table 2)

Five patients presented with lesions of both the 9 th and 10th cranial nerves manifesting as paralysis of the palate and vocal cords. Six patients complained of diplopia. A unilateral deficit in the 6th cranial nerve was detected in two cases and a bilateral deficit in one. No deficit was detected in the 3rd, 4th or 6th cranial nerves in the other three patients and was thought to be an early involvement of the nerve without a detectable neurological deficit. One patient presented with bilateral proptosis.

Generalised symptoms and signs (table 3) Sixteen (53\%) patients complained of diffuse headaches and, of these, only eight had papillodedema. Three patients gave a history of convulsions. Three patients had bouts of unconsciousness and two of these were admitted in an unconscious condition. Radiographic investigations Plain radiography was performed in all. Thirteen had demineralisation of the clinoid processes due to raised intracranial tension. Erosion of the petrous apex was seen in nine and separation of sutures in four patients. Ventriculography was performed in 19 patients. The findings were suggestive of a cerebellopontine angle space occupying lesion producing blocking of the

Table 2 Signs and symptoms of extension of the epidermoid beyond the cerebellopontine angle

\begin{tabular}{ll}
\hline Symptoms & \multicolumn{1}{l}{ Signs } \\
\hline $\begin{array}{l}\text { 1. Nasal intonation-3 } \\
\text { dysphagia-3 }-3\end{array}$ & 1. $\begin{array}{c}9 \text { th and } 10 \text { th cranial nerve } \\
\text { deficit }-5\end{array}$ \\
$\begin{array}{l}\text { hoarseness-1 } \\
\text { Diplopia-6 }\end{array}$ & 2. 6th cranial nerve deficit-3 \\
3. Bilateral proptosis-1 & 3. Bilateral proptosis-1 \\
\hline
\end{tabular}

Table 3 Generalised symptoms and signs of raised intracranial tension

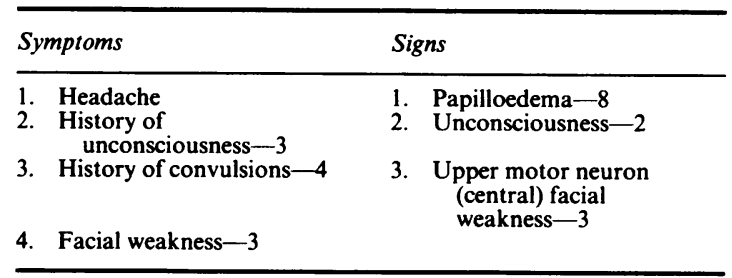

aqueduct, distortion and displacement of the 4th ventricle and triventricular hydrocephalus in each. Carotid angiography was performed in three and vertebral angiography in seven patients. All demonstrated an avascular lesion of the cerebellopontine angle with hydrocephalus. Computerised tomography was performed in seven patients, showing a hypodense lesion in the cerebellopontine angle in all. None enhanced with contrast (fig).

Surgery (table 4) Twenty-seven patients were treated surgically. The posterior cranial fossa approach was used in all and was combined with a middle fossa approach in four. Twelve patients required ventricular shunts to control raised intracranial tension prior to definitive surgery.

Since 1983 an electrocautery technique has been used to cauterise unresectable epithelium in the tumour bed. The bipolar diathermy was used at those sites where it was possible to coagulate the epithelium without causing damage to important neurovascular structures.

Operative findings in all patients included a sac or cyst-like lesion. It was not possible to determine the site of origin of the epidermoid due to its invasive nature. All the material excised at the time of surgery was sent for histopathologic examination, bacterial and fungal culture. All specimens were identified as epidermoids by the histopathologists and all cultures were negative.

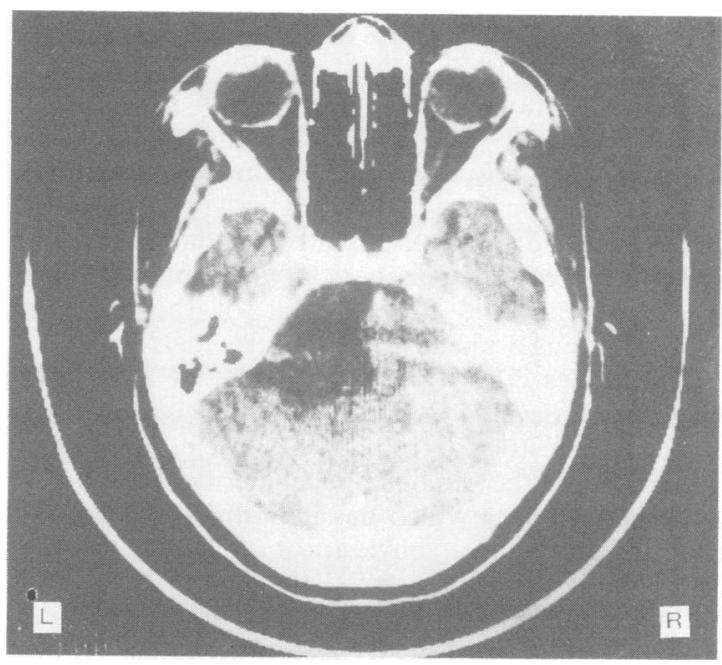

Fig CT scan of a cerebello-pontine angle epidermoid. Note its extension to the parasellar region. It is characteristically hypodense and does not enhance with contrast. 
Table 4 Surgical management

Total number of cases-27

Ventricular shunts prior to definitive surgery-12

Posterior cranial fossa approach-27

Combined posterior \& middle cranial fossa approach-4

Partial excision-22

Total excision-5

Complications Meningitis was seen in three patients, who developed a cerebrospinal fluid leakage through the operative site. Four patients developed worsening of 7 th cranial nerve weakness to total palsy. Five patients developed a 9 th or 10 th cranial nerve palsy.

Pre-operative mortality Three patients expired before surgery could be attempted; all died of coning due to raised intracranial tension. Post mortem examination in each revealed epidermoids of the cerebellopontine angle.

Post-operative mortality One patient died one month following surgery from a myocardial infarction.

Follow-up To date, the longest period of follow-up is 15 years. A partial excision was performed in this patient and he appears to be free of symptoms. Reformation of the residual epithelial has occurred in four patients. All developed reformation of the epidermoid within four years of the original surgery. Two were re-operated via the original postfossa approach. A partial excision was possible. The epithelial tags were coagulated. To date, both are asymptomatic. Of the two other patients, one died of unrelated causes and the other was advised to have close observation. Six patients were treated with coagulation of the epithelial remnants and, to date, none have developed symptoms or signs of reformation of the epidermoid. The maximum period of follow-up with these patients is 3 years.

\section{Discussion}

There are many theories regarding the origin of epidermoids; these have included embryonic inclusions, ${ }^{67}$ trauma and differentiation from multipotential cell rests ${ }^{8}$ and epithelial remnants. The cysts have also been postulated to be neuro-ectodermal in origin' $^{9}$ or to arise from pial tissues in the plexus tufts. ${ }^{10}$ Gacek" argued that epidermoids originate from epithelial cells from Seesels pouch, which may become encased within the fibrocartilage of the foramen lacerum during cephalic flexure, while others state that their capsules consist of a thickening of arachnoid mater ${ }^{12}$ and develop within it. None of our patients had definite history of trauma. We have not been able to determine the site of the epidermoids. A true epidermoid is that which has its nidus of squamous epithelium present at birth and may be found anywhere in the temporal bone, depending on where the cell rests may be situated. ${ }^{13}$ While epidermoids in the ear are most often infected, those of the cerebellopontine angle are usually sterile. However, both behave in a similar manner by expanding and eroding bone. Recent biomathematical analyses suggest that epider- moid lesions grow linearly at a rate similar to skin, rather than exponentially as most neoplasms. ${ }^{14}$ is

Epidermoids are known to the otologists by the synonym cholesteatoma and must be distinguished from the entity cholesterol granulomas. Cholesterol granulomas always contain cholesterol from haemorrhages and are not lined by stratified squamous epithelium..$^{16-18}$ None of our patients had otorrhoea and all had an intact tympanic membrane. It is well known that epidermoids of the cerebellopontine angle do not present with otorrhoea and may occur in an otherwise normal temporal bone. ${ }^{19}$

Some investigators ${ }^{201}$ have reported involvement of the 7th cranial nerve as the most common sign and first lesion to occur followed by an unilateral hearing loss. Our study has confirmed this. However, others ${ }^{2223}$ have reported a unilateral hearing loss as the first presenting sign. All agree, however, that epidermoids involve the facial nerve very early. By contrast, it tends to be involved much later by acoustic neuromas..$^{24} \mathrm{This}$ is because the epidermoid tends to "strangle" the 7th nerve and reduce its blood supply. ${ }^{25}$ An acoustic neuroma may stretch the nerve but impulses can still be conducted.

In some reports ${ }^{26}{ }^{27}$ trigeminal neuralgia was the most common presenting symptom. In this study trigeminal neuralgia was seen in only four patients. Its cause may be either local irritation from cholesterol seeping through the cyst wall or compression from a vascular loop against the nerve root entry zone. ${ }^{16}$ The 6 th cranial nerve was involved in three patients. To date, we have not been able to find any other report of an epidermoid of the cerebellopontine angle involving the 6th nerve.

Some investigators ${ }^{28}$ have found headaches to be the most common symptom and our series had confirmed this. Others note that changes in mental status occurred more often. ${ }^{29}$ None had mental changes in our series.

Recurrent aseptic meningitis is a rare presentation. ${ }^{30-34}$ This has been explained by investigators as the leakage of cholesterol into the cerebrospinal fluid causing chemical (aseptic) meningitis. Steroids have been found to be a useful treatment for this condition. In the absence of meningitis, the proteins in the cerebrospinal fluid are not elevated..$^{336}$

Diagnostic investigations Investigative techniques to determine the site, nature, and extent of lesions of cerebellopontine angle are many. However, plain radiography is the simplest and is often informative. Plain radiography often shows a sharply defined erosion with smooth margins, showing a definite osteitic reaction but without other evidence of previous temporal bone inflammation. ${ }^{24}$ Audiology helps confirm the presence of a retrocochlear lesion and determines the function of the 7th and 8th cranial 
nerves ${ }^{37}$ as well. Auditory brainstem responses have been found to be useful in differentiating various lesions of the cerebellopontine angle. ${ }^{38}$ Other investigations include ventriculography, angiography and pneumoencephalography. ${ }^{16}$ However, these invasive studies have largely been replaced by non-invasive diagnostic imaging methods such as computed tomography $y^{390}$ and magnetic resonance imaging ${ }^{4 / 16}$ which show the lesion, determine it vascularity, detect raised intracranial tension and help identify satellite pathologies, if any. These techniques guide the surgeon in the choice of surgical approach.

\section{Treatment}

Epidermoids present to otologists and neurosurgeons. There is a dichotomy in philosphy between the two disciplines in the surgical management of these lesions.

Small epidermoids can be totally removed via the translabyrinthine approach. ${ }^{42}$ Others have tried to preserve hearing and facial nerve function with the retrolabyrinthine approach. ${ }^{434}$ However, many otologists prefer fistulisation (exteriorisation) of the epidermoid via a mastoidectomy so that the debris does not accumulate.

Most neurosurgeons ${ }^{45}{ }^{16}$ prefer to attempt to excise the lesion through a craniotomy without fistulisation.

We prefer not to exteriorise epidermoids as it is our opinion that there is a risk of infection and probable intracranial complications. We attempt to excise the epidermoid while acknowledging that it is difficult to do so completely. We coagulate the epidermoid tags, wherever it is safe to do so, to minimise the chance of reformation. To our knowledge there have been no reports of this technique in the literature.

We thank Dr S K Pandya for permitting us to use his medical records.

\section{References}

1 Eekhof JLA, Thomeer RTWM, Bots G, Th AM. Epidermoid umour in the lateral ventricle. Surg Neurol 1985;23:189-92.

2 Boggan JE, Davis RL, Zorman G, Wilson CB. Intrasellar epidermoid cyst. $J$ Neurosurg 1983;58:411-5.

3 Russel DS, Rubinstein LJ. Congenital tumours of maldevelopmental origin. In: Edward Arnold, ed. Pathology of Tumours of the Nervous System, London, 1977:24-64.

4 Nager GT. Epidermoids involving the temporal bone, clinical radiological and pathological aspects. In: Laryngoscope 1975; Suppl 2:1-22.

5 Scott M. Epidermoid tumour (cholesteatoma) of the lateral cerebral ventricle. J Neurosurg 1957;14:110-13.

6 Paparella MM, Rybak L. Congenital cholesteatoma. In: Otolaryngol Clin North Am 1978;1:113-20.

7 Higashi K, Wakuta Y. Epidermoid tumor of the lateral ventricle. Surg Neurol 1976;5:363-5.

8 Reeves DL. Epidermoid (mixed) tumors of the central nervous system. J Neurosurg 1967;26:21-4.

9 Aimi K. Role of the tympani ring in the pathogenesis of congenital cholesteatoma. Laryngoscope 1983;93:1140-6.
10 Bailey P. Cruveilhiers: Tumeurs Perlées. Surg Gynaecol Obstet 1920;32:390-1.

11 Gacek RR. Diagnosis and management of primary tumours of the petrous apex. Ann Otol, Rhinol Laryngol 1975;Suppl 18:1-20.

12 Portmann M, Sterkers JM, Characon, Chouard H. Tumours of the Internal Auditory meatus and surrounding structures. In: The Internal Auditory Meatus. London: Churchill Livingstone, 1975:193-246.

13 Meyerhoff WL, Truelson J. Cholesteatoma staging. Laryngoscope 1986;96:935-9.

14 Kline LB, Gralbraith JG. Parasellar epidermoid tumour presenting as painful ophthalmoplegia. J Neurosurg 1981;54:113-7.

15 Alvord EC. Growth rates of epidermoid tumours. Ann Neurol 1977;2:367-70.

16 Sabin HI, Bordi LT, Symon L. Epidermoid cysts and cholesterol granulomas centred on the posterior fossa. Twenty years of diagnosis and management. In: Neurosurgery 1987;21:798-805.

17 Rosenberg RA, Hammerschlag PE, Cohen NL, Bergeron RT, Reede DL. Cholesteatoma vs. cholesterol granuloma of the petrous apex. Otolaryngol Head Neck Surg 1986;94:322-7.

18 Sataloff RT, Myers DL, Roberts BR, Feldman MD, Mayer DP, Choi HY. Giant cholesterol cysts of the petrous apex. Arch Otolaryngol Head Neck Surg 1988;114:451-3.

19 Flood LM, Kemink JL. Surgery in lesions of the petrous apex. Otolaryngolic Clin North Am 1984;17:565-75.

20 Linthicum FH, Schwartzman JA. Tumors of the temporal bone. In: An Atlas of Micropathology of the Temporal Bone. London: WB Saunders, 1974:70-80.

21 Mathog RH, Viscomi G. Otologic manifestations of retrocochlear disease. In: Paparella MM, Schumrick D, eds. Otolaryngology, Vol. II, 2nd ed. Philadelphia: WB Saunders, 1986:1898-1919.

22 Peron DL, Schuckneckt HF. Congenital cholesteatoma with other anomalies. Arch Otolaryngol 1975;1:498-505.

23 Kerr AG, Smyth DL. Congenital cholesteatoma of the temporal bone-a case report. Laryngoscope 1967;77:86-8.

24 Compere WE, Valvassori $G$. The radiologic examination of the petrous portion of the temporal bone. In: Radiographic Atlas of the Temporal Bone, Book 1, pp. 1-51. Philadelphia: American Academy of Otolaryngology and Ophthalmology.

25 Antoli-Candela F, Stewart TJ. The pathophysiology of otologic acial paralysis. Otolaryngolic Clin North Am 1974:7:309-30.

26 Baumann CHH, Bucy PC. Paratrigeminal epidermoid tumours. J Neurosurg 1956;13:455-68.

27 Hori T, Numata H, Hokama Y, Muraoka K, Takami M. Saito Y. Trigeminal pain caused by a parapontine cyst. Surg Neurol 1983;19:517-9.

28 Grant FC, Austin GM. Epidermoids: Clinical evaluation and surgical results. $J$ Neurosurg 1950;7:190-8.

29 Rosenbluth PR, Lichtenstein BW. Pearly tumour (epidermoid cholesteatoma) of the brain. Clinico Pathologic study of 2 cases. J Neurosurg 1960;17:35-42.

30 Leol O, Miles J. Epidermoid cyst in the brainstem. J Neurosurg 1978;48:811-3.

31 Schwartz JF, Balentine JD. Recurrent meningitis due to an intracranial epidermoid. Neurology 1978;28:124-9.

32 Tomlinson BE, Walton JN. Granulomatous meningitis and diffuse parenchymatous degeneration of the nervous system due to an intracranial epidermoid cyst. J Neurol Neurosurg Psychiatry 1967;31:73-5.

33 Cantu RC, Ojemann RG. Glucosteriod treatment of keratin meningitis following removal of a fourth ventricle epidermoid tumour. J Neurol Neurosurg Psychiatry 1968;31:73-5.

34 Sansregret A, Morrissette $Y$. The radiological investigations of the petrous bone in meningitis of unknown origin. Neuroradiology 1971;2:94-6.

35 Obrador S, Lopez-Zafra JJ. Clinical features of the epidermoids of the basal cisterns of the brain. J Neurol Neurosurg Psychiatry 1969;32:450-4.

36 Tytus JS, Pennybacker J. Pearly tumours in relation to the central nervous system. J Neurol Neurosurg Psychiatry 1956;19: 241-59. 
37 Sanders JW. Diagnostic audiology. In: Northern JL, ed. Hearing Disorders, 2nd ed. Boston: Little, Brown, 1984:25-39.

38 Cashman MZ, Rossman RN. Diagnostic features of the auditory brainstem response in identifying cerebellopontine angle tumours. Scand Audiol 1983;12:35-41.

39 Witten RM, Wade CT. Computed tomography in acoustic tumour diagnosis. In: House WF, Luetje CM, eds. Acoustic Tumours, Vol 1. Baltimore: University Park Press, 1979:253-77.

40 Curtin HD. CT of the acoustic neuroma and other tumors of the ear. Radiol Clin North Am 1984;22:77-105.

41 Koppel BS, Weinberger G. Radiologic evaluation of epidermoid cyst. $J A M A$ 1987;79:209-12.
42 De La Cruz A. The transchochlear approach to meningiomas and cholesteatomas of the cerebellopontine angle. In: Brackman DE, ed. Neurological Surgery of the Ear and Skull Bone. New York: Raven Press, 1982:353-60.

43 Nedzelski JM, Tator CH. Hearing preservation: A realistic goal in surgical removal of cerebellopontine tumors. $J$ Otolaryngoly 1984;13:355-60.

44 Belal A. Retrolabyrinthine surgery: Anatomy and Pathology. Am J Otol 1986;7:29-33.

45 Sekhar LN, Schramm VL, Jones NF, et al. Operative exposure and management of the petrous and upper cervical internal carotid artery. Neurosurgery 1986;19:967-82. 